\title{
TEMPAT PENGOLAHAN KOPI DI CIKINI
}

\author{
Christoforus Davin ${ }^{1)}$, Sutarki Sutisna ${ }^{21}$ \\ 1)Program Studi S1 Arsitektur, Fakultas Teknik, Universitas Tarumanagara, christdavin23@gmail.com \\ 2) Program Studi S1 Arsitektur, Fakultas Teknik, Universitas Tarumanagara, sutarkis@gmail.com
}

\begin{abstract}
Abstrak
Di masa sekarang kebutuhan sosial dan gaya hidup menjadi sebuah fenomena dimana pergi ke sebuah tempat untuk rehat dari rutinitas menjadi sebuah kebutuhan, khususnya di kota metropolitan seperti Jakarta, dari latar belakang tersebut maka Kawasan Menteng, Cikini adalah tempat terjadinya rutinitas yang sangat intens antara satu tempat ke tempat lain guna mencapai sesuatu. Dari pernyataan tersebut maka Cikini Coffee Roastery adalah sebuah jawaban yang dapat memenuhi kebutuhan dan kegiatan di daerah Cikini, khususnya untuk para pekerja, mahasiswa, dan kedai - kedai kopi berbagai kalangan di Kawasan tersebut. Lewat bentuk bangunan yang interaktif dan terbuka dengan jembatan yang melintang di bagian muka bangunan yang memberikan kesan ikatan jiwa. Nursery sebagai tempat rekayasa tumbuhan kopi berada di bagian belakang bangunan sebagai area interaksi antara bangunan inti dengan tapak, serta lingkungannya. Fungsi ruang di dalam bangunan memiliki orientasi untuk melayani para pengunjung, maupun komunitas yang berada di lingkungan sekitar tapak.
\end{abstract}

Kata kunci: fungsi; gaya hidup; interaksi; kegiatan; rutinitas

\begin{abstract}
Nowadays social needs and lifestyle become a phenomenon where going to a place to take a break from routine becomes a necessity, especially in a metropolitan city like Jakarta, from that background the Menteng Area, Cikini is a place of very intense routines between one place to other places to achieve something. From this statement, Cikini Coffee Roastery is an answer that can meet the needs and activities in the Cikini area, especially for workers, students, and coffee shops in various circles in the area. Through an interactive and open form of building with a bridge across the front of the building that gives the impression of a soul bond. Nursery as an engineered coffee plant is located at the back of the building as an area of interaction between the core building and the site, and the environment. The function of the space in the building has an orientation to serve the visitors, as well as the community in the area around the site.
\end{abstract}

Keywords: function; interactive; interaction; lifestyle; routines

\section{PENDAHULUAN}

Kawasan Menteng, Cikini, Jakarta Pusat adalah suatu daerah yang memiliki banyak tempat bersejarah dan tempat, khususnya kopi, selain perkantoran dan tempat penginapan. Umumnya masyarakat yang beraktifitas di Cikini merupakang seorang pelajar, pekerja, maupun pedagang, sehingga di waktu tertentu daerah Cikini sering kali dijadikan sebagai tempat berkumpul antar individu atau kelompok, hal ini terjadi karena para masyarakatnya memiliki kepentingan yang beragam, seperti untuk membahas masalah pekerjaan, pribadi, maupun menyendiri. Dari kesimpulan tersebut dapat dikatakan bahwa para masyarakat yang berkegiatan di daerah Cikini memiliki berbagai masalah, sehingga dibutuhkan suatu tempat yang 
tidak memiliki batasan ruang dan waktu untuk menyelesaikan permasalahan tersebut, ataupun untuk sekedar rekreasi dan bersosialisasi dengan sesamanya.

Di sisi lain, Daerah cikini dikenal dengan komunitas kopi dengan jumlah yang banyak, hal ini tentu berkaitan dengan masalah setiap individu yang beraktivitas di tempat tersebut. Kedai - kedai kopi yang berada di sepanjang jalan di kawasan Cikini mayoritas didatangi oleh para pekerja dan mahasiswa, hal ini menunjukan kedai - kedai kopi tersebut titik kumpul untuk sebagian besar masyarakat yang berkegiatan di kawasan Menteng, Cikini , Jakarta Pusat. Fenomena tersebutlah yang akhirnya membuat komunitas kopi hidup dikawasan Cikini, namun sangat disayangkan karena kedai - kedai kopi dengan skala kecil dan menengah yang mayoritas adalah wiraswasta mengalami kesulitan untuk mengolah biji kopi mentah milik mereka, selain itu untuk berbelanja kebutuhan dan alat - alat untuk usaha pun mereka harus menempuh perjalanan yang agak jauh untuk mendapatkannya. Oleh sebab itu Tempat Pengolahan Kopi di Cikini sangat dibutuhkan untuk mempersingkat waktu mereka dalam meracik kopi, dan mengembangkan usahanya, selain itu tempat ini juga dapat menjadi titik kumpul baru yang memiliki identitas tanpa harus menyingkirkan para pengusahan kopi di kawasan Menteng, Cikini, Jakarta Pusat.

Tabel 1. Prediksi Perbandingan jumlah produksi dan konsumsi kopi di Indonesia

\begin{tabular}{c|c|c|c}
\hline \multirow{2}{*}{ Tahun } & \multicolumn{2}{|c|}{ Proyeksi (Ton) } & \multirow{2}{*}{$\begin{array}{c}\text { Surplus } \\
\text { (Ton) }\end{array}$} \\
\cline { 2 - 3 } & Produksi & Konsumsi & \\
\hline $\left.2016^{*}\right)$ & 667.655 & 302.176 & 365.479 \\
$\left.2017^{* *}\right)$ & 672.283 & 304.231 & 368.052 \\
$2018^{* *)}$ & 686.344 & 306.183 & 380.161 \\
$\left.2019^{* *}\right)$ & 689.504 & 307.915 & 381.589 \\
$\left.2020^{* *}\right)$ & 692.906 & 309.771 & 383.136 \\
\hline \multicolumn{3}{|c|}{ Rata-rata } & 375.683 \\
\hline
\end{tabular}

Sumber: Asosiasi Ekspor Kopi Indonesia, 2017

Dari tabel diatas diperoleh kesimpulan bahwa peminat kopi akan terus bertambah setiap tahunnya jika kita lihat dari rata - rata, jumlah produksi tentu harus lebih tinggi daripada jumlah konsumsi, karena produk kopi memerlukan stock untuk disimpan maupun di distribusikan ke berbagai wilayah di Indonesia.

Tabel 2. Kenaikan harga kopi setiap setiap tahun

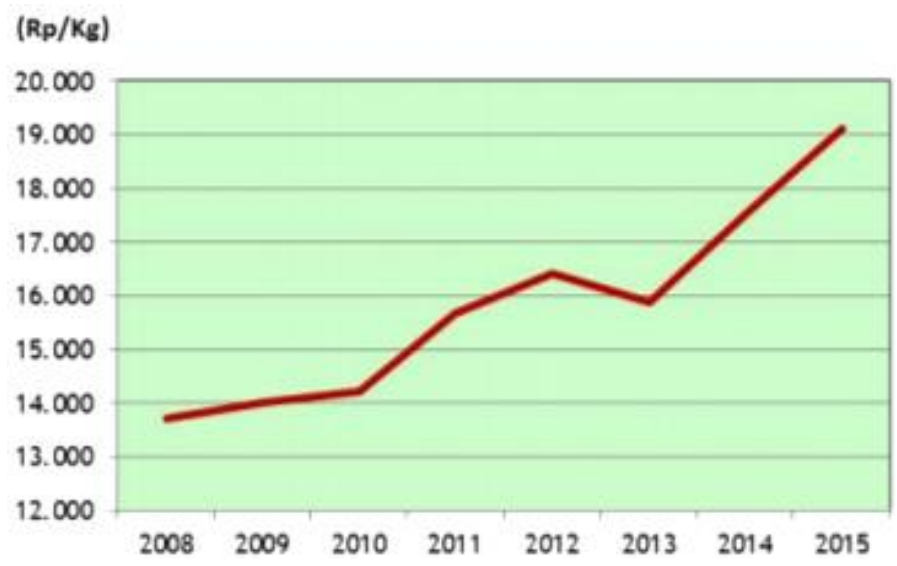

Sumber: Asosiasi Ekspor Kopi, 2018 
Tabel di gambar 2 menunjukan kenaikan harga setiap tahunnya berdasarkan masing masing jenis dari harga pokok yang beredar, sebagai contoh: pada tahun 2014 harga kopi arabica Simpang Gayo seharga 240rb, maka di tahun 2015 harga kopi tersebut menjadi 259rb, kareana ada kenaikan 19rb rupiah di tahun 2014, hal ini menunjukan bahwa usaha kopi memiliki pendapatan yang menjajikan, sehingga untuk membuat tempat pengolahan kopi di Cikini khususnya tidak perlu untuk diragukan lagi.

\section{KAJIAN LITERATUR}

\section{Open Architecture for The Third Place}

"Architecture is a technology. And it's involved in all of the different networks of system that produce architecture - including politics, economics, social, and cultural conditions. So architecture is already in technology." Elizabeth Diller (Diller Scofidio + Renfro Architect in 1981).

Dari Pernyataan tersebut diperoleh kesimpulan bahwa arsitektur adalah sebuah teknologi yang melibatkan berbagai macam aspek kehidupan yang menghasilkan sebuah karya yang didalamnya berisikan berbagai macam unsur seperti, kondisi politik, ekonomi, sosial, dan budaya yang kemudian terbentuk sebagai sebuah system.

\section{From Space to Place}

Sebagai contoh, suatu café yang terdiri dari ruang - ruang pokok penunjang ingin menjadikan suatu café tersebut sebagai "place" yaitu adalah sebuah tempat tanpa harus menghilangkan unsur café nya yaitu "space" yang artinya adalah ruang yang digunakan untuk minum kopi dan menyantap snack yang disediakan pada ruang café, karena tujuan dari café tersebut adalah mentransformasi space menuju place maka ukuran meja dibuat menjadi ukuran yang lebih besar sebagai pusat atau center dari area tersebut, sehingga dapat disimpulkan bawa place adalah sebuah tempat pusat untuk melakukan suatu aktivitas di ruang - ruang dari bangunan tersebut. (Building Dwelling Thinking - Martin Heidegger).

\section{The Third Place}

Ray Oldenburg menyebut "tempat pertama" seseorang sebagai rumah dan tempat tinggal seseorang. "Tempat kedua" adalah tempat kerja, di mana orang mungkin menghabiskan sebagian besar waktu mereka. Maka, tempat ketiga adalah "jangkar" kehidupan komunitas dan memfasilitasi dan mendorong interaksi yang lebih luas dan lebih kreatif dengan kata lain, tempat ketiga adalah suatu tempat untuk bersantai di depan umum, di mana kita berjumpa dengan wajah-wajah baru maupun yang sudah kita kenal. Great Good Place, Ray Oldenburg (1989, 1991) mengemukakan bahwa tempat ketiga penting bagi masyarakat sipil, demokrasi, keterlibatan sipil, dan membangun perasaan rasa tempat. Pendapat dan pandangan Oldenburg tentang tempat ketiga dapat disimpulkan dengan delapan karakteristik yang dimiliki, yaitu:
a. Tanah netral
b. Sama rata (persamaan status)
c. Percakapan adalah kegiatan utama
d. Aksesibilitas dan akomodasi
e. Pengunjung tetap
f. Profil rendah
g. Perasaan / pembawaan yang menyenangkan
h. Jauh dari rumah

\section{Open Architecture}

Dipl. Ing. Yusuf B. Mangunwijaya dri buku yang berjudul Wastu Citra, mengatakan bahwa "Masalah arsitektur bukan hanya soal statika bangunan agar kokoh dan tahan gempa, bukan juga harus nikmat ventilasinya dan elok efek psikologi interpenetrasi ruangan, dan bukan pula menyangkut paragmatik denah, penyusunan zona bisnis, ekonomi, industri, dan sebagainya, akan tetapi selalu menyentuh dimensi yang telah disentuh oleh Alam Raya pula". Dari 
pernyataan tersebut maka Open Architecture adalah sebuah konsep untuk terbuka terhadap segala hal dan kemungkinan yang terjadi, sekaligus proposal terhadap third place. Pada pelaksanaanya open architecture sebagai sebuah tempat ketiga atau third place yang menghubungkan antara tempat pertama yaitu tempat tinggal, dan tempat kedua yaitu tempat untuk bekerja sebagai program bagi sebagian besar masyarakat kota dengan harapan agar mereka memiliki sifat humanis terbuka, dinamis, dan produktif.

Wastu Citra, Dipl. Ing. Yusuf B. Mangunwijaya (1992 - 1995).

\section{METODE}

\section{Tempat dan Waktu Penelitian dan Perancangan}

Penelitian dilaksanakan pada tanggal 28 Juni 2019 di Kawasan Cikini, Menteng Jakarta Pusat tepatnya di kavling sebelah Gereja Babtis Indonesia, Cikini, dan Bangunan Menteng Huiss. Cikini menjadi tapak yang dipilih karena dikenal dngan rutinitas masyarakat disana yang bersifat urban, serta memiliki angka produktivitas yang tinggi. Selain itu faktor pendukung seperti gaya hidup dan tempat - tempat bersejarah yang menjadi warna tersendiri bagi Kawasan Menteng, Cikini.

\section{Metode Penelitian dan Perancangan}

Metode yang dilakukan adalah metode fenomenologi, yaitu dalam semua proses observasi, perhatian pengamat harus menuju kepada objek dan menghilangkan semua hal yang bersifat subyektif. Semua bentuk pendapat yang sudah ada sebelumnya termasuk keinginan, perasaan, dan sikap perlu untuk diabaikan selama melakukan observasi sehingga bersifat netral dalam pengerjaannya. Berdasarkan Metode Perancangan, suatu pengantar untuk Arsitek dan Perancang, Gunawan Tjahjono, 1999.

\section{Perumusan Ide}

Perumusan ide atau gagasan utama dalam perancangan Tempat Pengolahan Kopi di Cikini ini didasarkan atas 3 aspek, yaitu :

a. Perumusan Ide Berdasarkan Objek Karena di kawasan memiliki ciri khas yaitu sebagai salah satu tempat komunitas kopi dengan skala besar di Jakarta, dan dengan perkembangan beragam jenis kopi beserta dengan kehidupan para penikmatnya, maka penulis mengambil objek rancangan berupa Tempat Pengolahan Kopi di Cikini.

b. Perumusan Ide Berdasarkan Tema

Tema proyek yaitu Open Architecture for The Third place diharapkan mampu menciptakan sebuah tempat yang bersifat terbuka, dapat menerima keberagaman masyarakat, mendorong masyarakat untuk berkomunitas serta menyediakan program yang berkaraker bagi kebutuhan masyarakat kota dan mendukung kehidupan kota.

\section{Identifikasi Masalah}

a. Para warga dan pekerjanya yang bersifat individualis, sehingga menambah angka stress yang tinggi akibat aktivitas yang dilakukan oleh para manusia yang ada di lingkungan tersebut, sehingga diperlukan sebuah wadah untuk memfasilitasi kegiatan social mereka.

b. Banyak kedai kopi di Kawasan tersebut, tetapi tidak memiliki tempat yang luas untuk menampung pengunjungnya, serta adanya pembatasan waktu dan kurangnya fasilitas untuk pengolahan kopi, khususnya mesin roasting, dan peralatan yang memadai.

c. Adanya pembatas antara golongan atas dan bawah terutama secara financial dan SARA (Suku, Agama, Ras, dan Antar golongan). Informasi yang diberikan berdasarkan hasil dari observasi dan wawancara di Kawasan yang diteliti. 
1. Memberikan ruang dan waktu untuk pengunjung dan lingkungan agar dapat berinteraksi dan bersosialisasi dengan bebas untuk berekspresi.

2. Mendukung kedai - kedai kopi kecil dan menengah di sekitar Kawasan Cikini dalam hal pengolahan, peralatan, maupun pembelajaran bagi para calon barista.

3. Sebagai titik temu, tempat rekreasi dan berinteraksi untuk masyarakat sekitar sebagai pengguna area tersebut, sekaligus menjadi sebuah tempat transit untuk para pengguna transportasi umum maupun pribadi.

\section{Metode Pengumpulan Data}

Pengumpulan data dibagi menjadi 2 kategori yaitu:

Data primer

a) Studi lapangan

Dengan melakukan pengamatan langsung di lapangan yang diteliti meliputi proses pencatatan pola perilaku subyek (orang), obyek (benda),situasi, dan kondisi atau kejadian sistematik tanpa adanya pertanyaan atau komunikasi dengan individu-individu yang diteliti. Metode ini dilakukan tanpa perlu memberikan pertanyaan kepada responden. Peneliti melakukan pengamatan baik di lingkungan kerja alami, dan mencatat perilaku subyek penelitian. Untuk menilai tingkat akurasi data dan informasi yang disampaikan oleh setiap unit kerja yang dianggap perlu dengan pertimbangan:

- Adanya data atau informasi yang dinilai kurang layak atau meragukan, sehingga perlu diobservasi ke lapangan.

- Adanya unit organisasi yang spesifik dan cenderung mengarah kepada bentuk organisasi fungsional sehingga perlu pendalaman lebih khusus untuk perumusan dan pengkajiannya.

b) Dokumentasi

Dalam survey lapangan tersebut menggunakan media dokumentasi, dengan cara mengumpulkan dokumen-dokumen yang terkait dengan proses pencarian data, sehingga dihasilkan informasi serta bukti yang konkrit. Metode dokumentasi digunakan untuk:

- Mendokumentasikan kondisi eksisting tapak yang telah ditetapkan di kawasan Cikini.

- Mendokumentasikan suasana sekitar kawasan dan beberapa bangunan yang menunjukkan ciri khas kawasan.

\section{Data sekunder}

a) Studi literatur

Studi literatur yang digunakan sebagai referensi berupa buku, jurnal papers, artikel, dan karya ilmiah lainnya. Dalam perancangan Tempat Pengolahan Kopi di Cikini ini, studi literatur dimanfaatkan untuk pencarian data yang berkaitan dengan:

- Data yang terkait dengan kawasan, program dan tapak yang telah ditetapkan pemerintah. Kemudian dari data yang didapat tersebut kemudian dijadikan bahan pertimbangan analisis proses perancangan.

- Literatur mengenai "Third place" dan "Open Architecture", karakteristik yang dimiliki dan isuisu yang berkaitan.

- Literatur mengenai Kopi dan perkembangannya.

b) Studi Preseden

Studi kasus yang digunakan sebagai referensi berdasarkan proyek-proyek arsitektur yang berkaitan dengan isu Third place dan fenomena lingkungan yang dapat dilihat dari karakteristik proyek, program ruang, dan komposisi ruang. 


\section{Analisis Perancangan}

- Analisis Tapak

Tapak berada di area komersil Menteng, Cikini yang terletak di Jakarta Pusat dengan akses radial sehingga strategis dalam pembuatan meeting point yang ditujukan untuk semua kalangan. Di sekitar tapak terdapat pertokoan dan perkantoran. Pusat area komersil terdapat di bangunan Menteng Huiss dan sepanjang jalan RP. Soeroso dan Cikini Raya. Tidak jauh dari tapak terdapat Gedung Kopi sebagai perkantoran yang menangani eksport dan import kopi di Indonesia.

\section{- Analisis Fungsi}

Kawasan Menteng, Cikini memiliki banyak tempat kuliner dan kedai kopi, sehingga para pekerja dan mahasiswa sering berada disana untuk untuk sarapan pagi sampai dengan makan malam, bahkan sebagai tempat sebuah Asosiasi Eksport Kopi Indonesia (AEKI). Tak kalah penting pula bahwa Kawasan di Menteng, Cikini posisinya berdekatan antara kantor, universitas, permukiman, dan kostan.

\section{- Analisis Aktivitas}

Aktivitas masyarakat di Kawasan Menteng, Cikini mayoritas adalah pekerja kantoran, pedagang, pekerja kasar, dan mahasiswa. Kawasan Menteng, Cikini aktif dari jam 5 pagi yang diramaikan oleh aktivitas di stasiun Cikini dan Gondangdia, pedagang kaki lima untuk sarapan pagi, dilanjutkan dengan café - café dan restaurant di sekitar JL. Cikini Raya dan JL. RP. Soeroso, dan aktivitas perkantoran di wilayah tersebut.

\section{- Analisis Ruang}

Daerah Cikini dikatakan lengkap secara fasilitas ruang di dalam kawasannya, seperti tempat ibadah, perkantoran, bank, poliklinik, sekolah, pertokoan, universitas, pemukiman, bahkan kostan dan penginapan. Secara ruang dari fasilitas yang berada di Kawasan tersebut terlihat padat sehingga memerlukan beberapa ruang khusus untuk ruang terbuka dan sarana hiburan sebagai tempat masyarakat Kawasan tersebut bersosialisasi.

- Analisis Bentuk

Dalam perancangan arsitektur, analisis bentuk merupakan tahap terpenting dalam desain bangunan. Penampilan fisik di Kawasan Menteng, Cikini sangat beragam dari bangunan lama hingga bangunan yang paling modern, dari segi infrastruktur juga daerah ini banyak pembaharuan yang bersifat modern dan lebih lengkap dari segi efisiensi dan fungsi.

\section{- Analisis Struktur}

Dalam perancangan arsitektur, analisis struktur merupakan tahap proses penentuan efek dari beban pada struktur fisik dan komponen bangunan. Secara etimologi, analisis struktur adalah menggabungkan bidang mekanika teknik, teknik material dan matematika teknik untuk menghitung deformasi struktur, kekuatan internal, tekanan, reaksi tumpuan, percepatan, dan stabilitas. Dengan penyesuaian bentuk, fungsiserta tema perancangan sangat berpengaruh paa faktor-faktor lain seperti estetika, kondisi lingkungan (fondasi, pembebanan dari alam), ketersediaan material dan aspek ekonomis mungkin sangat berperan dalam penentuan kriteria formasi struktur.

- Analisis Utilitas

Dalam perancangan arsitektur, analisis utilitas merupakan tahap penentuan kriteria suatu kelengkapan fasilitas bangunan yang digunakan untuk menunjang tercapainya unsur-unsur kenyamanan, kesehatan, keselamatan, kemudian komunikasi dan mobilitas dalam bangunan. Analisis utilitas ini meliputi beberapa point diantaranya sistem plumbing, sistem elektrikal dan sistem komunikasi di Kawasan Menteng, Cikini, Jakarta Pusat. 


\section{DISKUSI DAN HASIL}

Ide awal dalam pembentukan sebuah desain bangunan dimulai dari tahap observasi keadaan sekitar, kemudian dilanjutkan dengan proses wawancara, dari hasil tersebut maka dioeroleh kesimpulan berupa:

\section{DESIGN SCHEME}

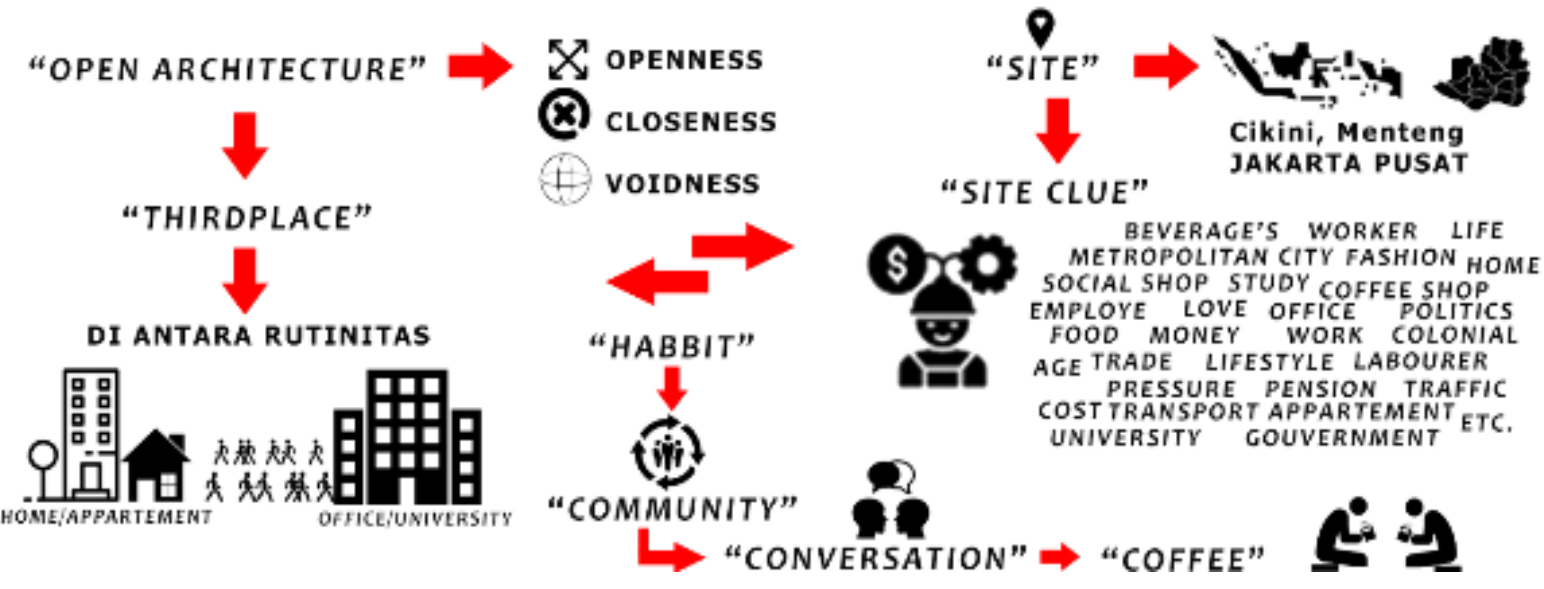

Gambar 1. Proses Penentuan Ide Rancangan

Sumber: Dokumentasi Pribadi

Setelah diperoleh ide pola rancangan dari hasil observasi dan wawancara, tahap yang akan dibuat, tahap selanjutnya melakukan penyesuain terhadap literatur dan sumber - sumber yang berpengaruh terhadap rancangan.
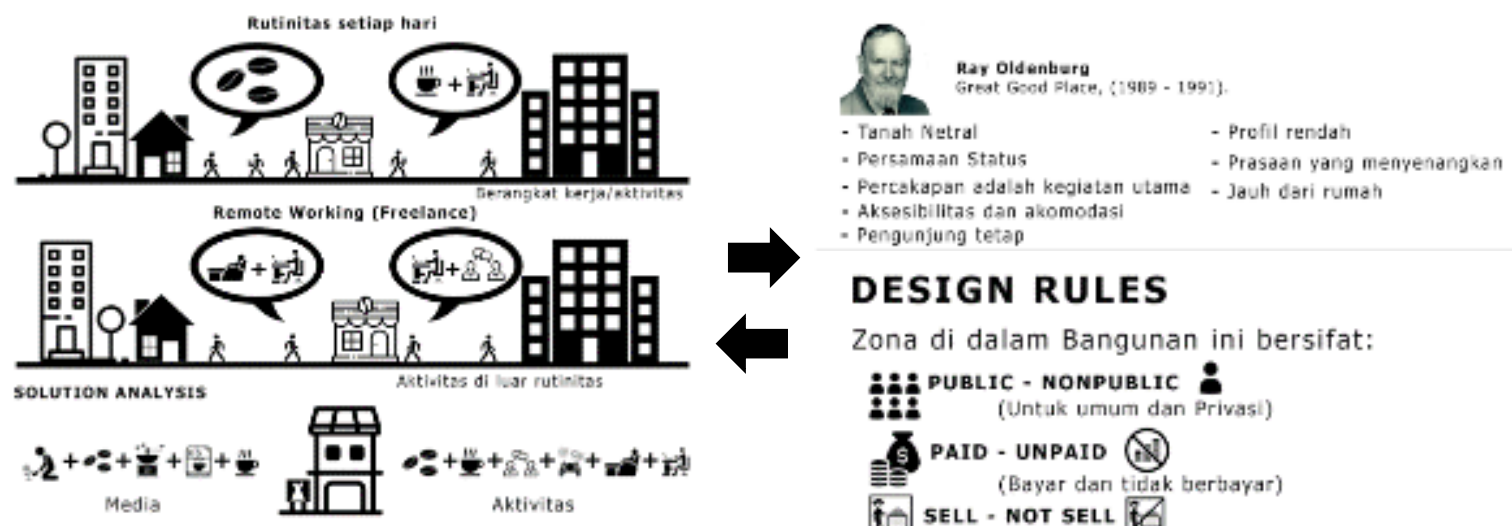

\section{DESIGN RULES}

Zona di dalam Bangunan ini bersifat:

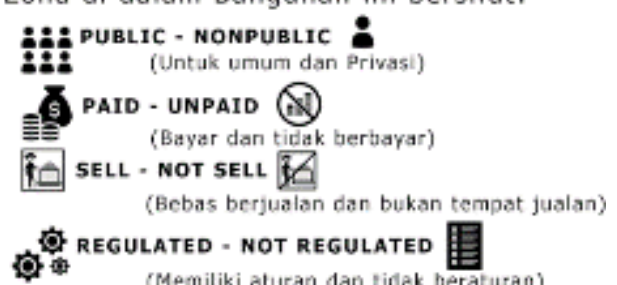

Gambar 2. Proses Transformasi terhadap data dan literatur Sumber: Dokumentasi Pribadi

Masa bangunan merupakan titik tengah dari tapak bangunan untuk memberikan kesan seimbang, selain itu bentuk masa bangunan dibuat silindris sebagai simbol "tidak pernah terputus" yang memberikan kesan bahwa sirkulasi ruang di dalam bangunan tidak ditemukan jalan buntu. 


\section{Proses Gubahan Massa:}

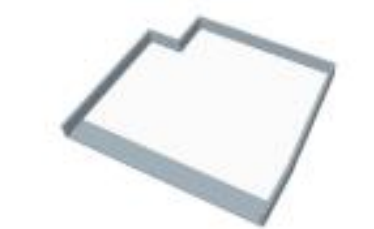

Bentuk tapak yang akan dirancang sebagal tempat pengolahan kopi.

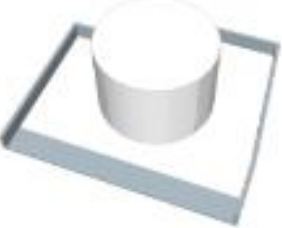

Sesuai dengan konsep bagian masa bangunan dibuat bentuk cilidris. sebagai implementasi dari bentuk biji kop

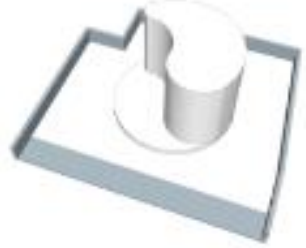

Bagian Massa bangunan dibagi menjadi 2 dan bagian sebelah dari bangunan yang telah di potong ditekan kebawah sebagai area ruang luar bangunan.

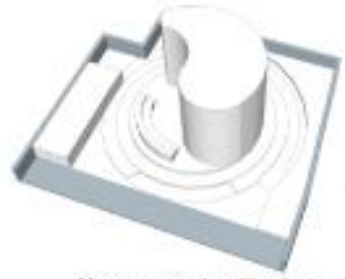

Masa yang bertingkat dibuat menghadap akses pejalan kaki sebaga simbol penerimaan. Area luar bangunan sebagai landscape dan area penunjang sesual dengan konsep.

Gambar 3. Proses Gubahan Masa

Sumber: Dokumen Pribadi

Bagian luar bangunan Cikini Coffee Roastery memiliki konsep terbuka, dan bentuk masa yang dirancang merupakan implementasi dari analogi tumbuhan kopi
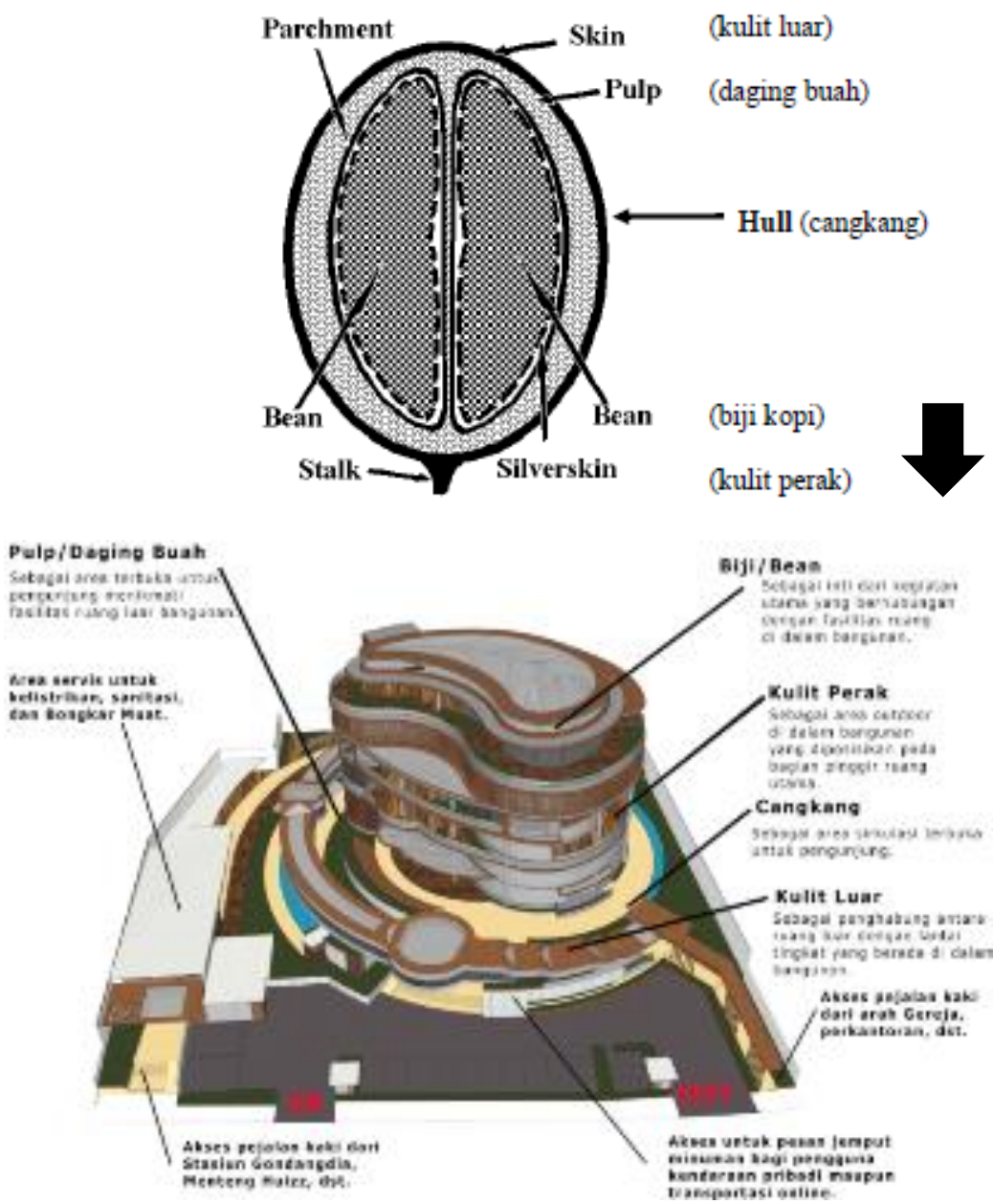

Gambar 4. Proses Implementasi Bentuk Sumber: Dokumen Pribadi

Bagian dalam bangunan memiliki ruang - ruang khusus yang merupakan implementasi dari unsur - unsur yang terkandung di dalam kopi, diluar konteks anatomi dan bentuk fisik dari biji kopi itu sendiri. 


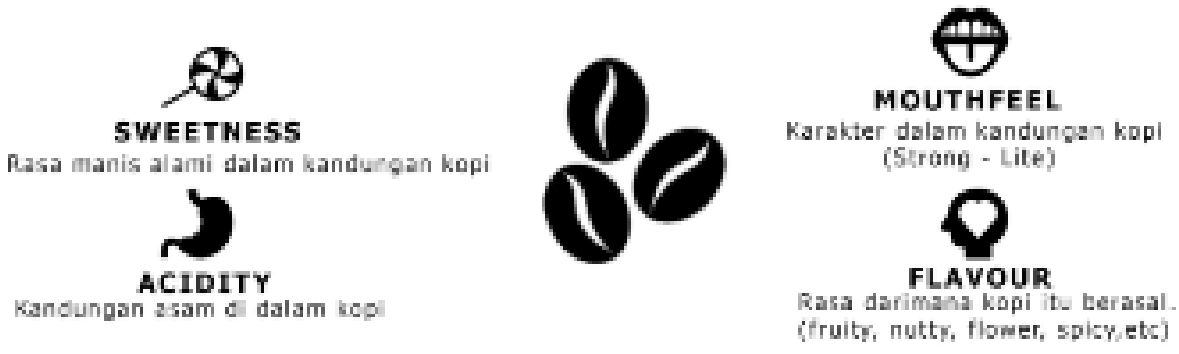

\section{Pembagian area di dalam bangunan:}

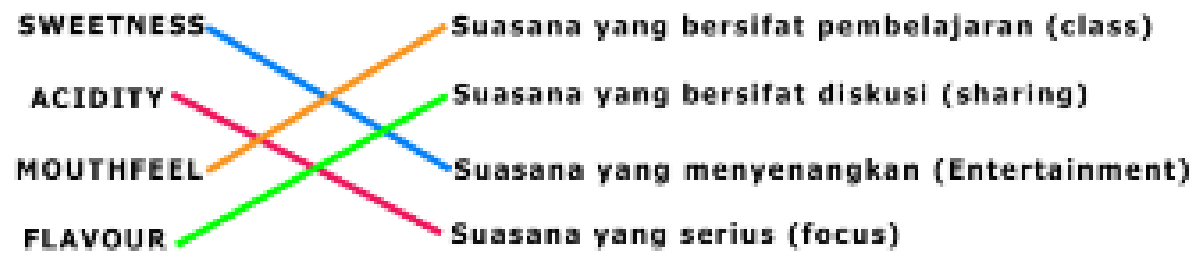

Gambar 5. Proses Implementasi Ruang Sumber: Dokumen Pribadi

Dari area - area yang sudah di tetapkan zonasinya, tahap selanjutnya adalah metransformasi ke dalam bagunan.
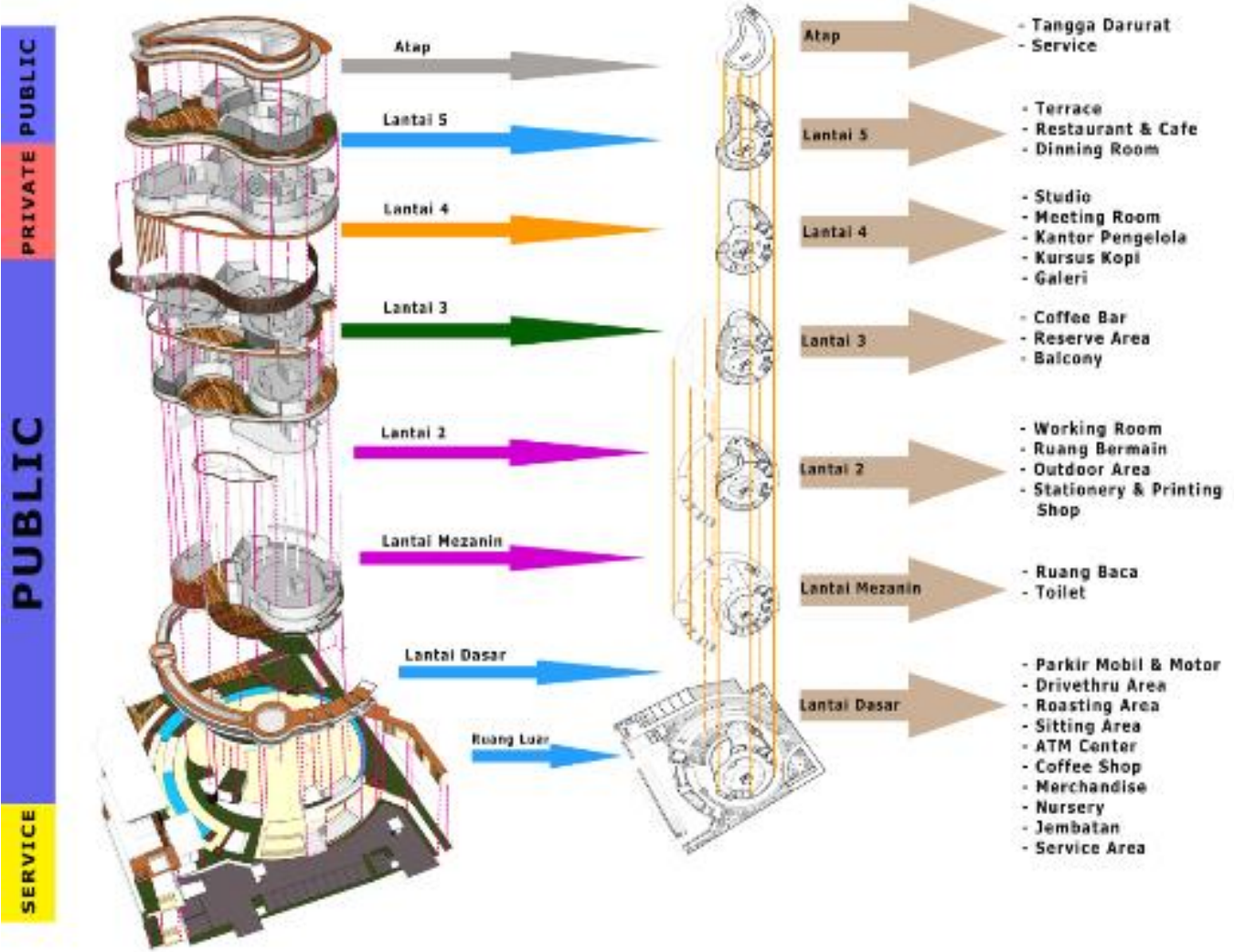

Gambar 6. Pembagian Ruang di dalam bangunan Sumber: Dokumentasi Pribadi

Dari awal perencanaan hingga proses perancangan menghasilkan keselarasan antara ruang luar dan ruang dalam bangunan yang menyatu dengan lingkungannya, sehingga menghasilkan hasil akhir yang memiliki karakter tersendiri di kawasan Menteng, Cikini. 


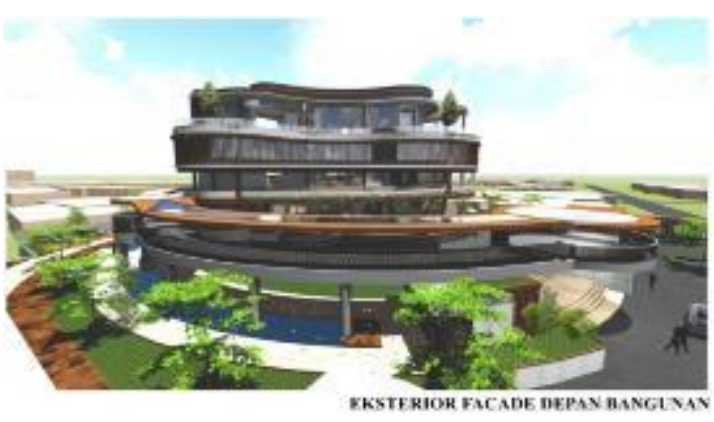

Gambar 7. Eksterior Depan

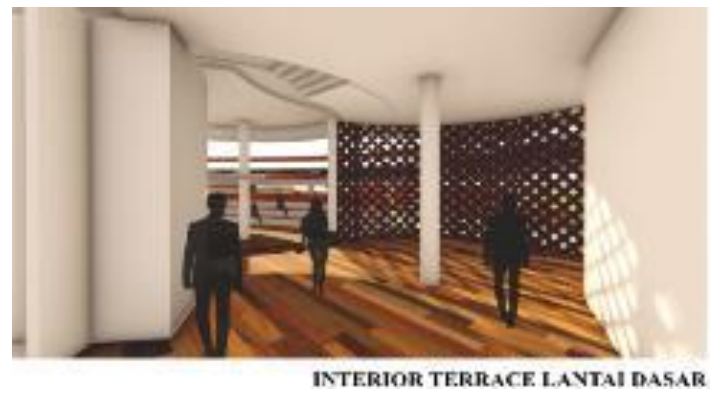

Gambar 9. Interior Terrace

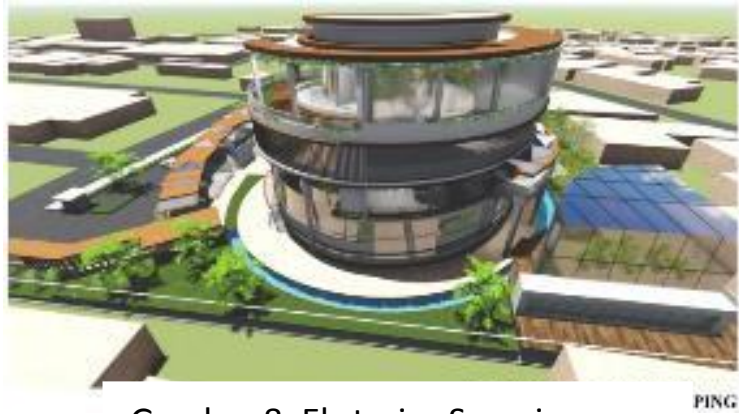

Gambar 8. Eksterior Samping

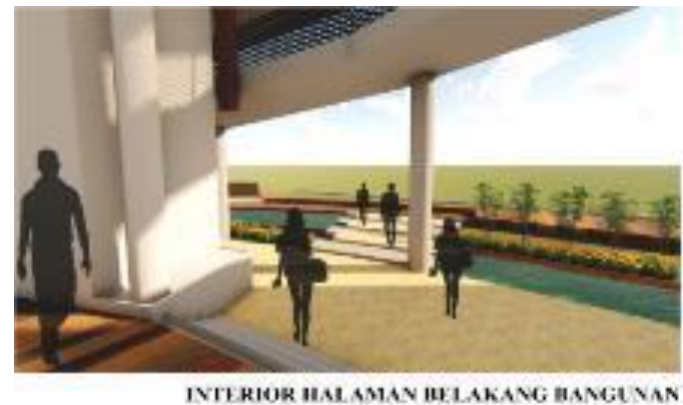

Gambar 10. Interior Halaman Belakang

Sumber: Dokumentasi Pribadi

\section{KESIMPULAN DAN SARAN}

Cikini Coffee Roastery merupakan bangunan yang memiliki peran sebagai penyokong kegiatan di sekitar lingkungannya, serta menjadi titik temu antar pengguna kawasan untuk saling berinteraksi dan memberikan dukungan lebih terhadap kedai - kedai kopi di sekitar bangunan dalam segi edukasi maupun penyediaan barang dan jasa.

\section{REFERENSI}

BPS Kota Administrasi Jakarta Pusat. (2017). Jakarta Pusat Dalam Angka 2017. BPS Kota Administrasi Jakarta Pusat.

Creswell, J. W. (1994). Research Design Qualitative, Quantitative, and Mixed Methods Approaches. University of Nebraska, Lincoln.

Heidegger, M. (2008). Building Dwelling Thinking. Paperback.

Mangunwijaya, Y.B. (1992). Wastu Citra, Jakarta, PT. Granedia. Jakarta.

Merkel, J. (2017). Richard Florida: The Rise of the Creative Class. In Schlüsselwerke der Stadtforschung (pp. 69-90).

Oldenburg, R. (1989). The great good place. Da Capo Press.

Tjahjono, G. (1999). Metode Perancangan, suatu pengantar untuk Arsitek dan Perancang.

White, A. T. (1997). No Title. Departement of Regional and City Planning.

https://www.un.org/sustainabledevelopment/wp-content/uploads/2019/07/Infographic-Lifeon-Land.pdf

https://www.smu.edu.sg/news/2018/08/27/smu-expands-city-campus-footprint-new-

sustainable-development-named-tahir-foundation

https://www.investopedia.com/terms/o/open-architecture.asp

https://en.wikipedia.org/wiki/Third_place 
http://dpu.kulonprogokab.go.id/article-49-klasifikasi-jalan-berdasarkan-status-dan-kelasjalan.html

https://jakarta.bps.go.id/pressrelease.html

http://data.jakarta.go.id/ca/dataset/data-penduduk-kota-administrasi-jakarta-pusat-tahun2018-1 
